\title{
Artificial Neural Network and Fuzzy Neural Network Algorithm for Financial Health Analysis of Indonesian SOEs
}

\author{
Handy Tantyo ${ }^{l}$, Nabyl Chataby ${ }^{l}$, Meirista Wulandari $^{2}$, Theresia Herlina R. $^{1}$ \\ ${ }^{1}$ Human Computer Interaction, Surya University, \\ Jl. M.H. Thamrin KM 2.7 Panunggangan Utara, Pinang, Tangerang, Banten, Indonesia \\ ${ }^{2}$ Electrical Engineering, Tarumanagara University, \\ Jl. Letjen. S. Parman 1 Grogol Petamburan, Jakarta
}

\begin{abstract}
The determining of financial soundness of SOEs company is regulated by the government through Decree of the Minister of SOEs KEP: 100 / BUMN / 2002. There are 8 parameters to be calculated for determining financial soundness such as ROE, ROI, cash ratio, current ratio, collection periods, inventory turnover, TATO, and ratio of total equity to total assets. From the calculation results based on these rules, there are 3 categories of companies, that is healthy, less healthy and unhealthy. To calculate the best parameters as a significant aspect to determining financial soundness, this research using neural networks method. In this paper, it compares the value of accuracy and learning rate with Artificial Neural Network and Fuzzy Neural Network method. Accuracy used as the fitness value of the Genetic Algorithm, to get the top three parameters from eight parameters to determining the financial soundness of SOEs companies. The result of this research both ANN and FNN get the same top three parameters: ROE, ROI, and Cash Ratio. In overall, artificial neural network or fuzzy neural network algorithm both suitable for use in the financial health analysis of SOEs companies.
\end{abstract}

Key words: Financial Soundness of SOEs Companies, Artificial Neural Network, Fuzzy Neural Network, Genetic Algorithm

\section{INTRODUCTION}

The technological fortunes have provided a vast source of information and communication from what humans already have. Although the role of information in a few decades lacks attention, the real need for information and communication is not less important than the needs of human clothing and food. Information is a key element that is implicitly embedded in the concept of planned development. Any development activity can only take place and achieve the goal if at every stage (planning, execution and oversight) based on adequate information. The rate of growth and accumulation of knowledge of the information age is increasing very rapidly exponentially [1].

The Association of Indonesian Internet Service Providers (APJII) said the number of internet users in Indonesia reaches 88 million people by the end of 2014 . The results of survey by APJII too in 2016, 132 million of 256 million people of Indonesia use the internet. $65 \%$ of people of Indonesia use the internet as a source of information. With the rapid development of technology in Indonesia, many aspects of information dissemination can be improved, not to mention information on corporate finance [2].

The government also sees that with the existence of financial transparency, every company can be monitored clearly how the financial situation and can prevent the existence of criminal acts such as money laundering and so forth. Important aspects that can be used as an indicator in improving the quality of the company one of them with the financial aspects. The most usual form of corporate financial information is a set of financial statements. The financial statements consist of various reports, such as income statement, capital change report, balance sheet, cash flow, and notes to the financial statements. From these data can be seen and calculated whether the company's finances are in a healthy condition or not. The calculation of the financial health of the company is also regulated by the government through the Decree of the Minister of SOEs KEP: 100 / BUMN / 2002.

Corresponding Author: Handy Tantyo, Surya University, Jl. M.H. Thamrin KM 2.7 Panunggangan Utara, +628995677755 
Jacob's research in 2013 [3], bank as intermediary institutions play a very important role in driving the economy of a nation. Banks in their role must be managed prudently and the need for special surveillance from the authority. As for the object of this research is State-Owned commercial bank listed on the Indonesia Stock Exchange the period 2010-2011.The purpose of this study was to assess the soundness of the government-owned commercial bank listed on the Indonesian stock exchange period 2010 - 2011 using CAMEL method. Government-owned commercial banks are believed to have an important role in stimulating public reliance in our Banking Industry Nationwide. Research results showed that 3 banks, Bank Mandiri, Bank BNI and BRI Bank Noted as "Sehat" while 1 Bank, Bank BTN Noted as "Cukup Sehat". While in our research, we use neural network methods to determine the financial soundness of companies. The subject companies are a State-Owned Enterprise.

Artificial Neural Network is the first classification method that we analyzed. According to Verma \& Srivastava [4], predictive algorithm based on neural networks are available and it proves superior to empirical methods of clinical staying. Aim of their research is to apply artificial neural network to heart disease prediction research. The Artificial Neural Network have been trained and tested on different input variables describing the patient's history. A network trained with a moderately high artificial mortality rate can improve the sensitivity of the model. Preliminary results shows that this system can be useful in daily routine practice of medical researchers and hospital clinicians. Further the trends in forecast by proposed method have been compared with the forecast by other available methods like linear model, moving average method, and fuzzy sets, their ANN model shows better results than other methods

One of the development of artificial neural network is Fuzzy Neural Network. Dahal \& Almejalli [5] research proposed genetic algorithm-based learning approach for a specific type of fuzzy neural network. The proposed approach consists of three stages: initializing membership functions of input and output variables by determining their centers and widths, engage the proposed approach to identify the fuzzy rules, and tunes the derived structure and parameters using a back-propagation learning algorithm. The result is the GA-based learning approach can identify relevant fuzzy rules from a training data set with a higher prediction accuracy than other approaches. According to the research, the architecture of FNN optimized by genetic algorithm. On the other hand, genetic algorithm used for optimizing parameter in both FNN and ANN.
Refers to Tsai, Eberle, \& Chu [6] feature selection and instance selection are two important data preprocessing steps in data mining. Genetic algorithms have been widely used for these tasks in related studies. Therefore, the aim of this study is to perform feature selection and instance selection based on genetic algorithms using different priorities to examine the classification performances over different domain datasets. The experimental results obtained from four small and large scale datasets using SVM and KNN classifier. In particular, there are four different data preprocessing approaches: feature selection, instance selection, feature selection + instance selection, and instance selection + feature selection. The small-scale experimental results show that performing feature selection first and instance selection second can make the classifiers provide slightly better classification results than performing instance selection first and feature selection second. On the other hand, in the largescale experiments, the classifiers sometimes perform better based on a combination of feature and instance selection than those based on feature and instance selection alone.

\section{EXPERIMENT}

\section{Modeling}

In the modeling part, will be divided into 4 parts, namely the company's financial soundness parameter, genetic algorithm, artificial neural network and fuzzy neural network

\section{Company's Financial Soundness Parameter}

As has been discussed in related work above [7], the assessment of a company's performance is a standard that has been established by each agency. From these results, the company or others can see feedback on the company's achievements.

The determination of financial soundness of companies under the State-Owned Enterprises is annually conducted. In this research, we will choose the best 3 parameters of 8 parameters determined by StateOwned Enterprises. The Company's financial soundness rating has 8 parameters are as follows [8];

\section{Return on Equity}

ROE (Return on Equity) is a ratio that indicates a company's ability to generate net income by using its own capital and generate net income available to the owner or investor. The higher the return on equity of the firm, the better management is to use the investor's capital to generate profit. Investors analyze ROE trends for individual firms and compare them with historical benchmarks and industry. 
Return on Investment

ROI (return on investment) presents the results or (rate of return) of a investment period. ROI is calculated based on each nominal invested (total capital). ROI is calculated based on actual cash flow. This ratio combines profitability financial factors into a rigorous equation that is intended to help organizations choose their most effective use of capital.

\section{Cash Ratio}

Sometimes analysts need to see the company's liquidity from a very conservative point of view. For example, a company may have guaranteed its receivables and inventory, or the analyst suspects a severe liquidity problem with inventories and receivables. Indicator

The company's best short-term liquidity is cash ratio. Cash ratio shows the direct liquidity of the company. If the company's cash ratio is too low, it indicates that the company has a direct problem with paying the bills.

\section{Current Ratio}

Current Ratio is the ratio most commonly used to analyze the working capital position of a company. This ratio is the ratio between current assets with current liabilities.

\section{Collection Periods}

Collection Periods is a ratio that shows how long (days) the sale is tied to the receivable or how long it takes since the company made the sale, up to the receipt of the cash payment

\section{Inventory Turn Over}

Inventory turnover is used to measure how many times the funds that are embedded in inventory rotate within a year.

\section{TATO}

Total asset turns over (TATO) shows the level of efficiency of the overall use of the company's assets in generating sales volume.

\section{Ratio of Total Equity to Total Assets}

The ratio of total equity to total assets shows the percentage of investment in total assets that have been purchased with funds derived from own capital.

\section{Genetic Algorithm}

Genetic algorithm is an algorithm used for data optimization process. With this method is expected that the selected data is not trapped in local minima so that can be obtained by global optima.

There are 3 main functions of crossover or crosslinking used to get new results that will be calculated by fitness.
1. Fitness is a function in which any new data will be considered in discrete form;

2. Mutation is a process that occurs so that a data can change characteristics depending on the environment (random function). Normally mutations are initiated at 2 percent.

3. At the end of the process will be selected the best chromosome seen from the value of fitness.

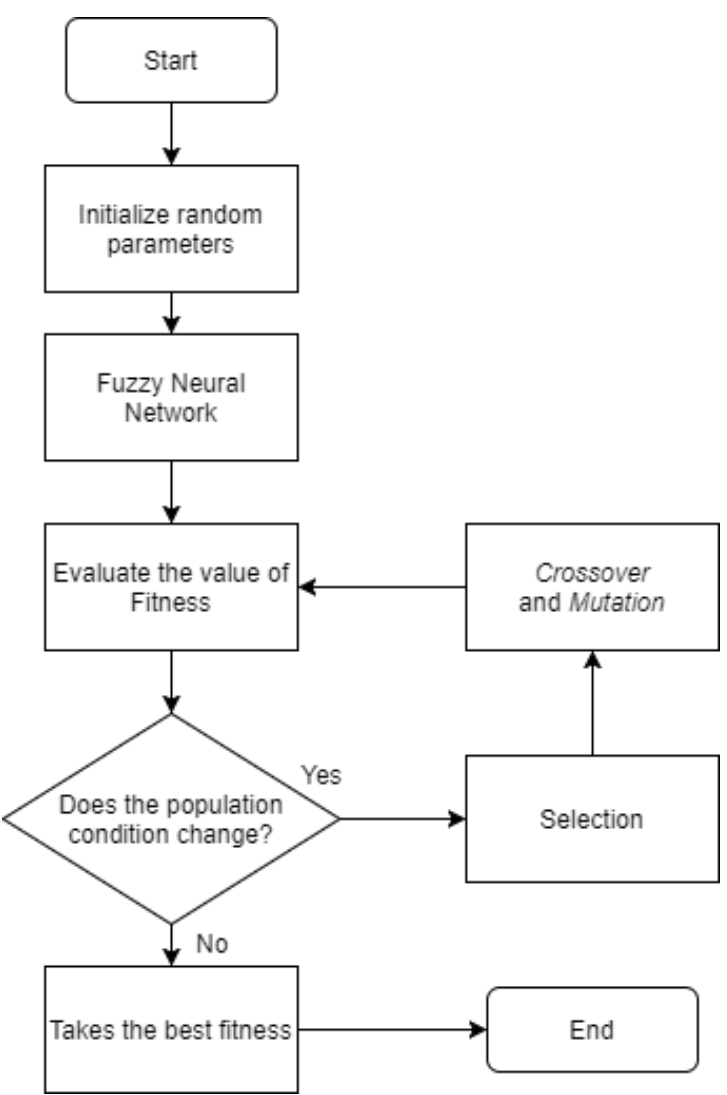

Figure 2. Flowchart Genetic Algorithm

This stage will be more discussed the process of its genetic algorithm. The initial process of this stage is the initialization of parameters randomly. Four new populations will be formed using combinations of 8 parameters to 3 parameters per population. Once the four parameters have been established, then enter the fuzzy neural network of 5000 iterations. The function of the fitness value is determined by the accuracy of the clashing process. Of the 4 existing populations, two populations will be selected with the highest fitness value.

Then again 2 new populations consisting of crossover and or mutation of the 2 best population marriages with initialization of mutation will be $2 \%$. The two new populations will be incorporated into the ANN and FNN function again for graded accuracy after 5000 iterations. The two new populations will be compared with a pair of previous parents to be evaluated. 


\section{Artificial Neural Network}

Artificial Neural Network or commonly abbreviated as ANN is an algorithm in the field of machine learning, which uses the network concept of a group of processing units formed like neural networks in humans.

Artificial Neural Network learning is perfect for problems where training data is resistant to noise, complex sensor data, such as input from cameras and microphones. In addition, ANN suitable for the following problems [9]:

1. The input attributes are possible or highly correlated or independent of each other. The input value can be an actual value.

2. The output of the target function can be either discrete, real value, or vector of some real or discrete value attribute. The value of each output is a real number between 0 and 1 , which in this case corresponds to the researcher's belief

3. Training example may contain errors. ANN learning method is strong enough to noise in training data.

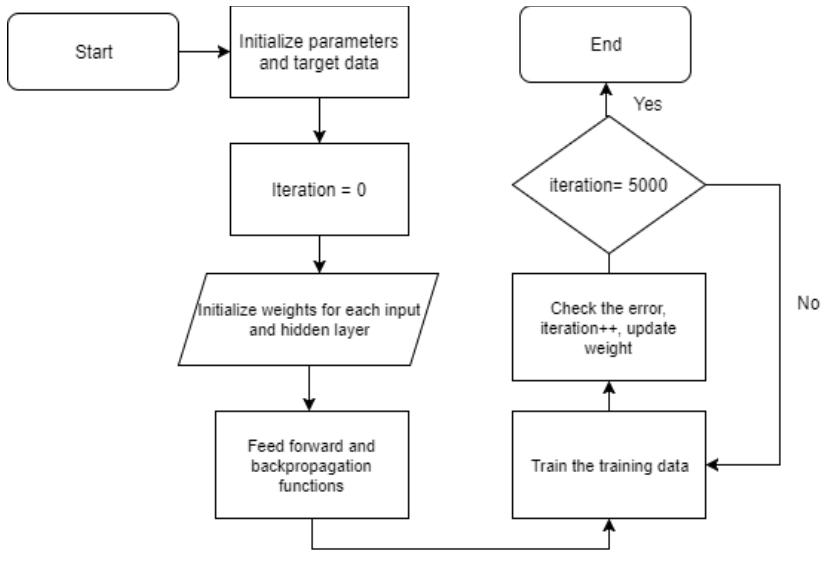

Figure 4. Flowchart Neural Network

This stage serves as a machine learning so that the output of the training data is close to even the same as the target or the actual result. The first thing to do is to initialize the parameters to be selected in the genetic algorithm process. Then the parameters that have been selected will be included in the fuzzy function to change the weight value to be inserted into the hidden layer. The process to calculate from layer to layer using feedforward, while to calculate error on the layer using backpropagation. Data will be trained until the last data 5000 times. An error check will be used for the accuracy level which will be processed as the fitness value of the genetic algorithm process.

\section{Fuzzy Neural Network}

It is a method from combining fuzzy logic with artificial neural network which allows for mapping into the artificial neural form. Fuzzy neural network has layers are input layer, fuzzy input later, conjunction layer, fuzzy output layer, and output layer [10].

These are the steps of fuzzy neural network method [11]:

1. Define the universe and divides it into sections with equal interval length

2. Obtain distribution statistic from historical data in each interval. Divide the interval into several sub-intervals of the same length according to the order of data distribution

3. Define each set of fuzzy Ai based on the interval that has been formed in step 2, fuzzily data, and range $i$ is the number of intervals that have been formed. The membership value of the fuzzy Ai set is determined to be $0,0.5$, or 1 . Then fuzzified the historical data based on the linguistic value of $\mathrm{Ai}$

4. Determine the fuzzy logic relation

5. Establish layers on the network (hidden network)

6. Training data to estimate fuzzy logic relations in the next steps

7. Divide each interval coming from step 2 into several subintervals of the same length

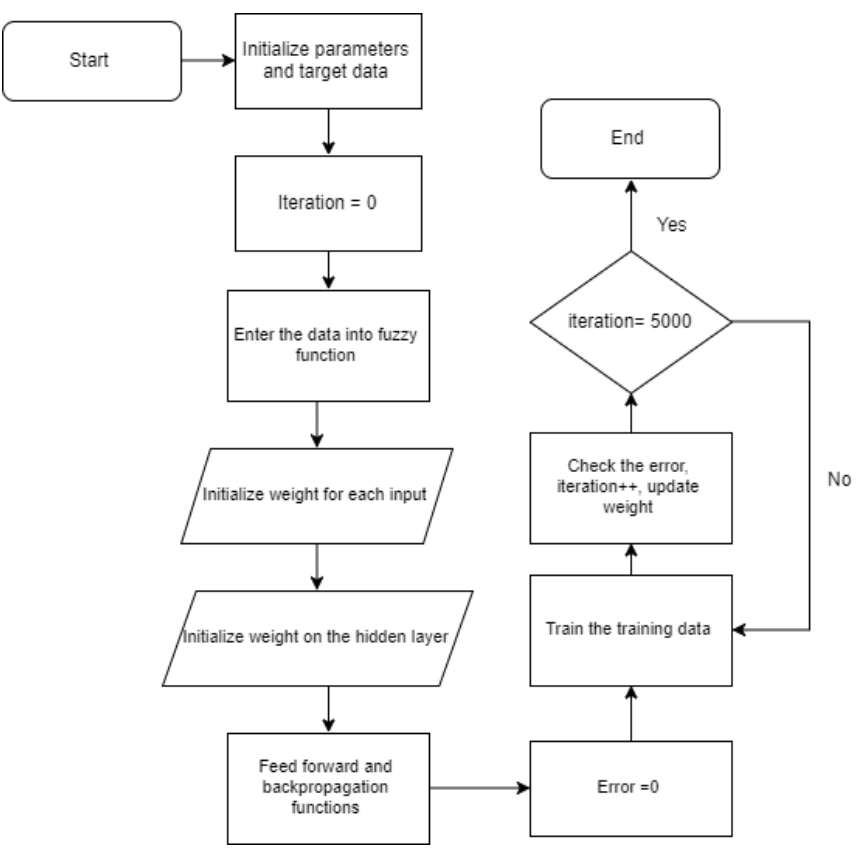

Figure 5. Flowchart Fuzzy Neural Network

Basically, the principles of ANN and FNN are the same. But the difference between FNN and ANN lies in its fuzzy process. If the input of ANN is the original value, the FNN input will be processed first to enter in 
the membership function. In the fuzzy neural network, the fuzzy is used to direct the value to a node before entering the neural network process. For more details, the following fuzzy neural network architecture is generated.

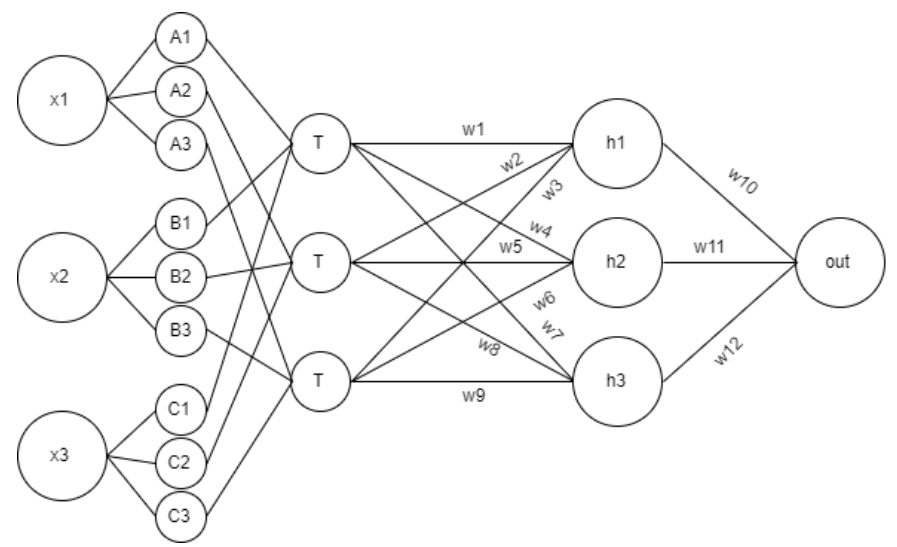

Figure 6. Fuzzy Neural Network Architecture

From the fuzzy neural network architecture above, A1-A3, B1-B3, and C1-C3 are fuzzy processes. The value of $\mathrm{T}$ is derived from predefined rule. As for $\mathrm{T}$ to out process, is a multilayer neural network algorithm with 1 hidden layer. While the architecture in Neural Network has almost the same shape, but does not have 2 layer membership function.

\section{CALCULATION}

\section{Artificial Neural Network}

There are basically two techniques in calculating the two types of machine learning. The first technique is called feedforward and the second is called backpropagation. Feedforward is used to calculate the activation values present in all neurons. Whereas in backpropagation used to recalculate from neuron output up to the earliest process. With backpropagation, the error value can be reduced well [9].

The algorithm on feedforward is as follows.

$$
N e t=\sum_{i=0}^{n} \mathrm{w}_{\mathrm{i}} \mathrm{X}_{\mathrm{i}}+\mathrm{b}_{\mathrm{j}}
$$

where $w$ is the weight of each neuron, whereas $\mathrm{x}$ is the input given by the user. In addition bj is the value added to each layer. One node has two layers: Net as described above and another is $\sigma$ (net) which is used to be an inverting function that can be used as a hidden unit output. The algorithm is as follows.

$$
\sigma(n e t)=\frac{1}{1+e^{-n e t}}
$$

where the net value is obtained from the previous calculation, and e is the mathematical constant value derived from the word Euler. The value of $\mathrm{e}$ is
2.7182818284. Meanwhile, to update the value of each weight and also bias using backpropagation techniques as below

$$
\delta_{\mathrm{k}}=\mathrm{o}_{\mathrm{k}}\left(\mathrm{l}-\mathrm{O}_{\mathrm{k}}\right)\left(\mathrm{t}_{\mathrm{k}}-\mathrm{O}_{\mathrm{k}}\right)
$$

where the delta function is an equation for calculating the error value of the output layer. The $\mathrm{O}_{\mathrm{k}}$ value is the output value of the feedforward calculation. For $t_{k}$ is the target value corresponding to the actual result or value predicted by the researcher. While the error on each hidden layer is like this

$$
\delta_{\mathrm{h}}=\mathrm{oh}(\mathrm{l}-\mathrm{Oh}) \sum_{\in} \mathrm{W}_{\mathrm{kh}} \delta_{\mathrm{k}}
$$

The end of the backpropagation process is to update the value of each weight calculated by this formula

$$
\mathrm{w}_{\mathrm{ji}}=\mathrm{w}_{\mathrm{ji}}+\Delta \mathrm{w}_{\mathrm{ji}} \text { where } \Delta \mathrm{w}_{\mathrm{ji}}=\eta \delta_{\mathrm{j}} \mathrm{x}_{\mathrm{ji}}
$$

where $\eta$ is the learning rate which is the value given as the learning ability of a system.

\section{Fuzzy Neural Network}

As the explanation on the method part, this algorithm is a combination of two previous algorithms, namely fuzzy logic, and artificial neural network. The calculation of this algorithm also involves feedforward and backpropagation techniques. But the difference is the addition of fuzzy logic techniques that we use with the standard representation of shoulder curves, which are written with formulas like this [12].

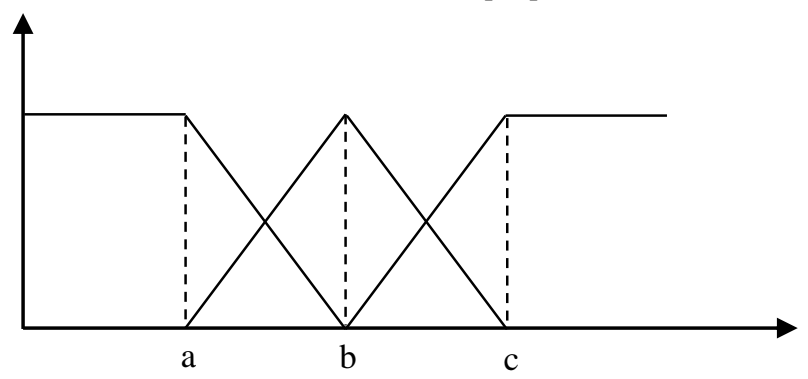

Figure 1. Fuzzy Rules

$$
\mu[x, a, b, c]= \begin{cases}1, & x \leq a \text { or } x \geq c \\ \frac{x-a}{b-a}, & a \leq x \leq b \\ \frac{c-x}{c-b}, & b \leq x \leq c\end{cases}
$$

where each parameter has a value of a, b, c different from one another adjusted to the financial soundness of companies under the State-Owned Enterprises. 


\section{RESULT AND DISCUSSION}

In this result, we will discuss about the algorithms used in this study. The input used in this algorithm is 3 parameters of 8 parameters. As for FNN, the 3 inputs must enter fuzzification (input membership function) first to be used as new input. The membership function is as follows.
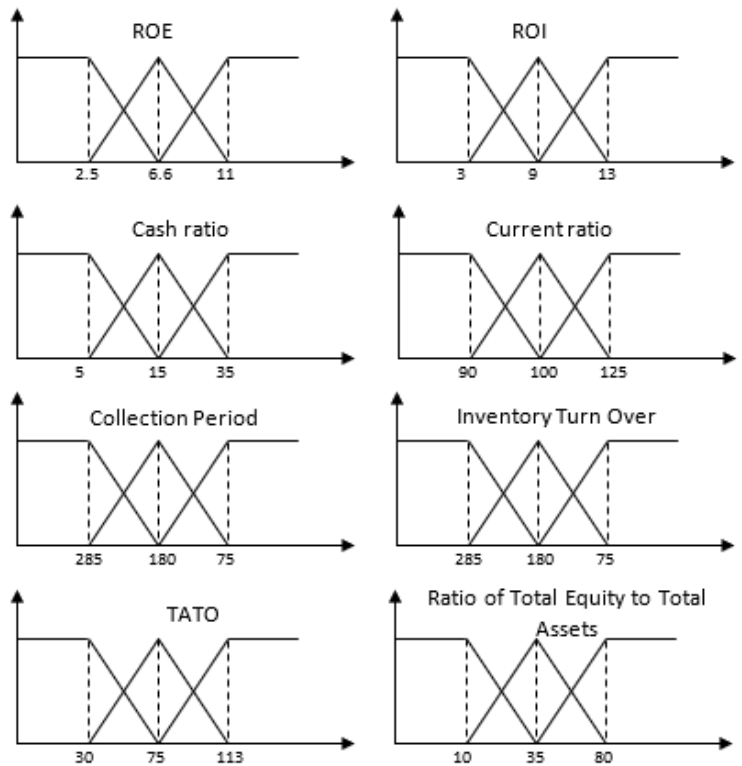

Figure 7. Membership Function of FNN

The twenty-four rules are used to clarify the soundness of state-owned enterprises. The categories of health levels are as follows.

\begin{tabular}{|c|l|l|}
\hline No & \multicolumn{1}{|c|}{ Target/Output } & \multicolumn{1}{c|}{ Criteria } \\
\hline 1 & $0.1-0.3$ & Not Healthy \\
\hline 2 & $0.4-0.6$ & Unwell \\
\hline 3 & $0.7-0.9$ & Healthy \\
\hline
\end{tabular}

These eight inputs will be processed with genetic algorithm. The population formed in GA is 4 pieces. Each of these populations is processed using 2 classifiers namely Artificial Neural Network and Fuzzy Neural Network. Both classes have their own fitness results. Taken 2 the best fitness score for parents. After that obtained the best population results are ROE, ROI and cash ratio with fitness value is 89.894264 for ANN and 83.153702 for FNN. ROE, ROI and Cash Ratio are reviewed again using MAPE to know forecasting ability of ANN and FNN algorithm.

The algorithm used is artificial neural network, fuzzy neural network, and genetic algorithm. For more details the discussion is as follows.

\section{Genetic Algorithm}

Table 1. Fitness ANN and FNN

\begin{tabular}{|c|c|c|c|}
\hline No & Population & Classifier & Fitness \\
\hline \multirow{2}{*}{1} & \multirow{2}{*}{$\begin{array}{l}\text { ROE, ROI, Ratio } \\
\text { of Total Equity to } \\
\text { Total Assets }\end{array}$} & ANN & 86.542 \\
\hline & & FNN & 81.312 \\
\hline \multirow{2}{*}{2} & \multirow{2}{*}{$\begin{array}{c}\text { ROI, Cash Ratio, } \\
\text { Current Ratio }\end{array}$} & ANN & 60.884 \\
\hline & & FNN & 73.621 \\
\hline \multirow{2}{*}{3} & \multirow{2}{*}{$\begin{array}{l}\text { Cash Ratio, } \\
\text { Inventory Turn } \\
\text { Over, Ratio of } \\
\text { Total Equity to } \\
\text { Total Assets }\end{array}$} & ANN & 61.896 \\
\hline & & FNN & 44.721 \\
\hline \multirow{2}{*}{4} & \multirow{2}{*}{$\begin{array}{l}\text { Collection Period, } \\
\text { Inventory Turn } \\
\text { Over, TATO }\end{array}$} & ANN & 36.573 \\
\hline & & FNN & 21.598 \\
\hline \multicolumn{4}{|c|}{ Result } \\
\hline \multirow{2}{*}{5} & \multirow{2}{*}{$\begin{array}{l}\text { ROE, ROI, Cash } \\
\text { Ratio }\end{array}$} & ANN & 89.085 \\
\hline & & FNN & 88.061 \\
\hline
\end{tabular}

Table 1. contains four randomly selected populations with their fitness value obtained from the formula (1-Etotal) * 100. In the genetic algorithm process, these parameters will be checked again to obtain new population results (new children). Furthermore, both the best parents and new children enter the crossover process and also mutation process. After six times iteration, 4 same populations will be resulted which indicate the process of this algorithm is complete.

The results obtained from the initialization of these 4 initial parameters signify the same results in the artificial neural network algorithm and also fuzzy neural network. They have a fitness value of 89.894264 for ANN and 83.153702 for FNN.

\section{Artificial Neural Network vs Fuzzy Neural Network}

In the following discussion will be divided into 2 parts, namely learning rate and also the total error rate where the total error of each algorithm obtained from the first 5000 iterations. 


\section{Learning rate}

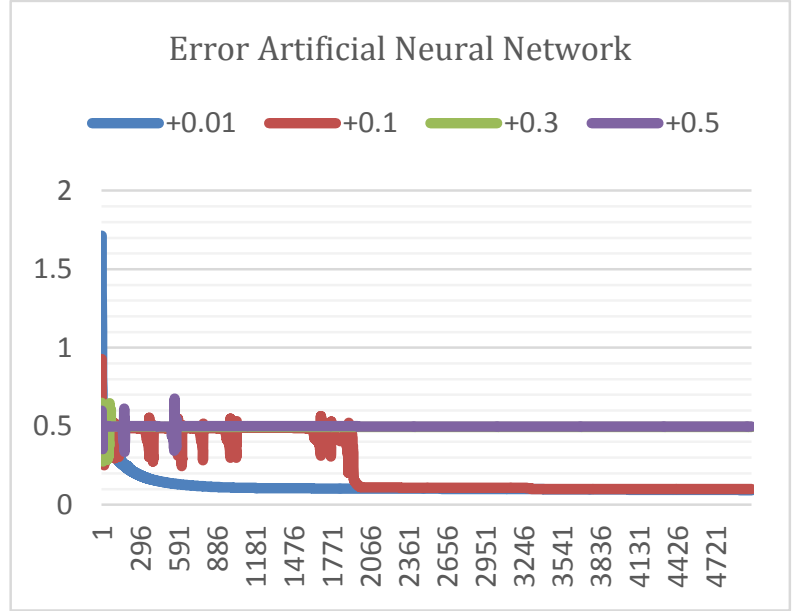

Figure 8. Error total for ANN

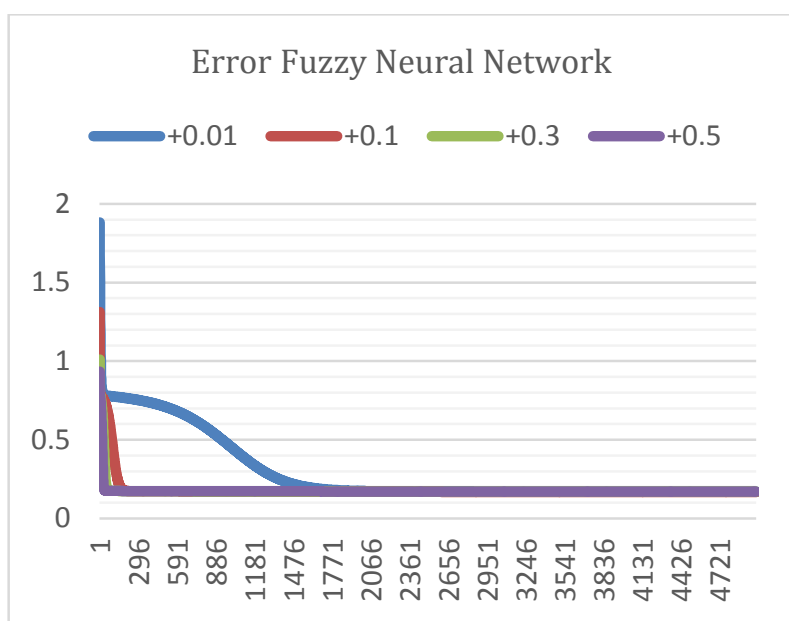

Figure 9. Error total for FNN

Learning rate that will be discussed in this section is in terms of aspects of error obtained by the system. Figure 7 and figure 8, are among the graphs obtained in populations taken randomly by the system. Error image on ANN shows learning rate 0.01 is the best learning rate with difference of 0.007 with learning rate 0.1 . While the error image on fuzzy neural network shows learning rate 0.1 is the best learning rate after learning rate 0.3 with 0.002 difference.

When compared in terms of learning rate can be said fuzzy neural network has better flexibility than neural network. This is because the error on the neural network is quite low only at the learning rate of less than 0.3 , while the fuzzy neural network learning rate 0.01 to 0.5 has a relatively low error rate. This is because ANN at learning rate 0.3 and above, the accepted algorithm is easy to enter local minima.

\section{MSE for each population}

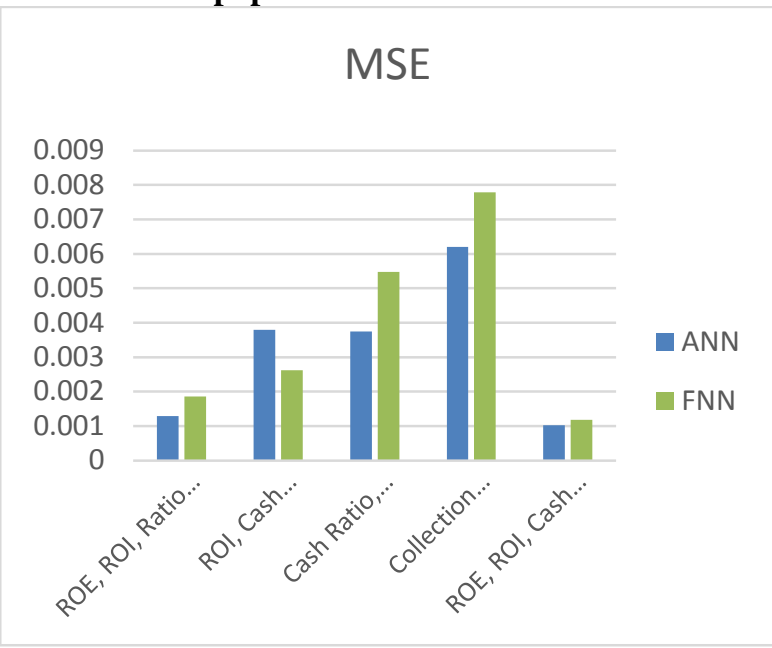

Figure 10. MSE for ANN and FNN

The graph above shows the MSE values obtained by soft computing neural network and soft computing fuzzy neural network. From four randomly selected populations, both ANN and FNN have their respective advantages. ANN excels in population of ROE, ROI, Ratio of Total Equity to Total Assets, population of Cash Ratio, Inventory Turn Over, Ratio of Total Equity to Total Assets, population of Collection Period, Inventory Turn Over, Total Equity to Total Assets and population of ROE, ROI, Cash Ratio. While FNN excels in population of ROI, Cash Ratio, Current Ratio. On average, ANN's MSE is slightly better than FNN by $5.72 \times 10^{-4}$. However, this result has not been absolutely proven because ANN does not always have high accuracy values in all population. Therefore, further research is needed.

\section{MAPE}

It is the average of the overall percentage of error (difference) between the actual data and the forecasting data. Accuracy sizes are matched with time series data, and are shown in percentages. The MAPE formula is as follows.

$$
M A P E=\frac{1}{n} \sum_{t=1}^{n} \frac{\left|\hat{Y}_{t}-Y_{t}\right|}{Y_{t}} X 100
$$

The MAPE categories are as follows [13].

Table 2. MAPE forecasting rate

\begin{tabular}{|c|c|c|}
\hline No & MAPE & Interpretation \\
\hline 1 & $<10 \%$ & Highly accurate \\
\hline 2 & $10 \%-20 \%$ & Good \\
\hline 3 & $20 \%-50 \%$ & Reasonable \\
\hline 4 & $>50 \%$ & Inaccurate \\
\hline
\end{tabular}


According to MAPE formula above, obtained MAPE value on each classifier as follows.

Table 3. MAPE value ROE, ROI and Cash Ratio

\begin{tabular}{|c|c|c|}
\hline \multicolumn{3}{|c|}{ MAPE } \\
\hline $\begin{array}{c}\text { ROE, ROI, Cash } \\
\text { Ratio }\end{array}$ & ANN & $5.746076 \%$ \\
\cline { 2 - 3 } & FNN & $6.592579 \%$ \\
\hline
\end{tabular}

From the MAPE results described above, it can be concluded that the ANN and FNN classifier is highly accurate.

\section{CONCLUSION}

Financial health is an important aspect of a company. The most generic form for obtaining company financial information is a set of financial statements. The financial statements can be in the form of income statement, cash flow, balance sheet, changes in capital and so forth. One of the bodies issuing regulations on financial health is SOEs through SK. Minister of SOEs KEP: 100 / BUMN / 2002. This research uses 3 algorithm that is ANN, FNN and GA. In general, we conclude the following points:

1. Learning rate obtained from both artificial neural network and fuzzy neural network algorithms suggest that fuzzy neural network is more flexible or better than artificial neural network.

2. Accuracy results in this study, both ANN and FNN are not too different, but ANN still has better forecasting than FNN.

3. In the selection of the best parameters both ANN and FNN showed the same results of ROE, ROI and Cash ratio with each of its fitness values are 89.085 and 88.061.

4. Artificial neural network and fuzzy neural network suitable for use in the financial health problems of a company, because its have low MAPE level.

\section{REFERENCES}

[1] A. Ahmad, "PERKEMBANGAN TEKNOLOGI KOMUNIKASI DAN INFORMASI: AKAR REVOLUSI DAN BERBAGAI STANDARNYA," Jurnal Dakwah Tabligh, vol. 13, no. 1, pp. 137-149, 2012.
[2] APJII, "Penetrasi dan Perilaku Pengguna Internet Indonesia," 2016. [Online]. Available: https://apjii.or.id/content/read/39/264/SurveiInternet-APJII-2016. [Diakses 18 October 2017].

[3] J. K. D. Jacob, “Analisis Laporan Keuangan dengan Menggunakan Metode CAMEL untuk Menilia Tingkat Kesehatan Perbankan," Jurnal EMBA, pp. 691-700, 2013.

[4] T. Verma dan D. R. K. Srivastava, "Artificial Neural Networks based heart disease predictive Approach," International Journal of Application or Innovation in Engineering \& Management (IJAIEM), vol. 4, no. 3, pp. 29-32, March 2015.

[5] K. Dahal dan K. Almejalli, "GA-Based Learning For Rule Identification In Fuzzy Neural Networks," Applied Soft Computing, vol. 35, pp. 605-617, 2015.

[6] C.-F. Tsai, W. Eberle dan C.-Y. Chu, "Genetic algorithms in feature and instance selection," Elsevier, pp. 240-247, 2013.

[7] D. M. P. Iswahyudi, D. dan D. F. Azizah, "ANALISIS TINGKAT KESEHATAN PERUSAHAAN BERDASARKAN," Jurnal Administrasi Bisnis (JAB), pp. 98-104, 2016.

[8] BUMN, "Keputusan Menteri BUMN KEP100/MBU/2002 tanggal 04 Juni 2002,” 26 January 2002. [Online]. Available: http://jdih.bumn.go.id/lihat/KEP-100/MBU/2002.

[9] T. M. Mitchell, "Artificial Neural Network," dalam Machine Learning, McGraw-Hill Science/Engineering/Math, 1997, pp. 81-126.

[10] L. Fu, Neural Network in Computer Intelligence, McGraw Hill., 1994.

[11] A. Rahmadiani dan W. Anggraeni, "Implementasi Fuzzy Neural Network untuk," JURNAL TEKNIK ITS Vol. 1,, pp. A-403 - A 407, 2012.

[12] R. Full'er, "Fuzzy System," dalam Neural Fuzzy Systems, Turku, 1995, pp. 11-156.

[13] J. J. M. Moreno, A. P. Pol, A. S. Abad dan B. C. Blasco, "Using the R-MAPE index as a resistant measure of forecast accuracy," Psicothema, vol. XXV, no. 4, pp. 500-506, 2013. 